\title{
The Nebraska Mesonet: Technical Overview of an Automated State Weather Network
}

\author{
Martha Shulski, Stonie CoOper, Glen RoebKe, AND Al Dutcher \\ School of Natural Resources, University of Nebraska-Lincoln, Lincoln, Nebraska
}

(Manuscript received 15 October 2017, in final form 11 September 2018)

\begin{abstract}
The Nebraska Mesonet was established in 1981 as one of the nation's first automated state weather networks. "Automated" is defined by the nature of the observations being made and recorded by machine, as opposed to observations made and recorded manually. At the time of inception, the five observing locations were geared toward servicing agricultural production applications. The Nebraska Mesonet has grown to 69 stations (as of 2018) and is now a multipurpose environmental observing network under the Nebraska State Climate Office (NSCO). The network is composed of environmental observation stations, sited using best practices for mesoscale and microscale environment situations. Precise observations are acquired using highquality instrumentation, following manufacturer recommendations for calibrations and maintenance. Calibrations are performed in the NSCO calibration laboratory. Uses for the data include but are not limited to water management, drought monitoring, energy production, health, environmental research, animal management, and crop pest management. This paper provides a technical overview and history of the network, outlining current practices for station siting, maintenance, data quality assurance, and data utility.
\end{abstract}

\section{Introduction}

A myriad of in situ environmental observing networks are currently in operation throughout the United States for a variety of purposes. Networks are available for applications in fire weather (Zachariassen et al. 2003), climate (Diamond et al. 2013; COOP), transportation (Boselly et al. 1993, 90-93; Manfredi et al. 2005), aviation (Nadolski 1998), marine weather (Conlee and Moersdorf 2005), hydrology (Cifelli et al. 2005; Schaefer and Johnson 1992), and mesoscale meteorology (e.g., McPherson et al. 2007), among others. Fiebrich (2009) offers a comprehensive historical review of surface weather observations in the United States and illustrates the significant technological advancements and growth of automated networks throughout the 1900s.

The late 1980s saw considerable growth in the implementation of nonfederal mesoscale automated weather networks (Meyer and Hubbard 1992). A strong impetus for expansion of these nonfederal networks was the need for nonstandard variables (such as soil temperature and solar radiation) and a higher spatial and temporal density of observations. The operation and management of these mesoscale weather networks, or "mesonets," is primarily through respective state agencies or state climate offices.

\footnotetext{
Corresponding author: Martha Shulski,mshulski3@unl.edu
}

Temporal frequency of observations is also critical to be considered a mesonet, with hourly recording of data being a minimum frequency (Tucker 1997). Mahmood et al. (2017) provides an overview and status of mesonet operations in the United States. Robust mesonets exist throughout the country, such as in Oklahoma (McPherson et al. 2007) and west Texas (Schroeder et al. 2005). In the central United States, the coverage of mesonets is rather dense with established programs in North Dakota, South Dakota, Nebraska, Kansas, Wyoming, Colorado, Minnesota, Iowa, and Missouri.

Significant work has been performed on how to successfully design and implement such mesonets and to quality assure the data (e.g., Elliott et al. 1994). Preventative maintenance through site visits is a key step to ensuring quality data from a mesonet (Tucker 1997). The frequency of on-site visits varies by mesonet and is dependent on respective mesonet resources (Fiebrich et al. 2006). From three times per year to annually is the current standard range for state-run mesonets, with troubleshooting visits as needed. Routine sensor calibrations and data quality checks are also a fundamental step in the quality assurance (QA) process. Shafer et al. (2000) outlines four basic principles of QA for the Oklahoma Mesonet that include an instrument laboratory, field visits, automated computer routines, and manual inspection of the data. 


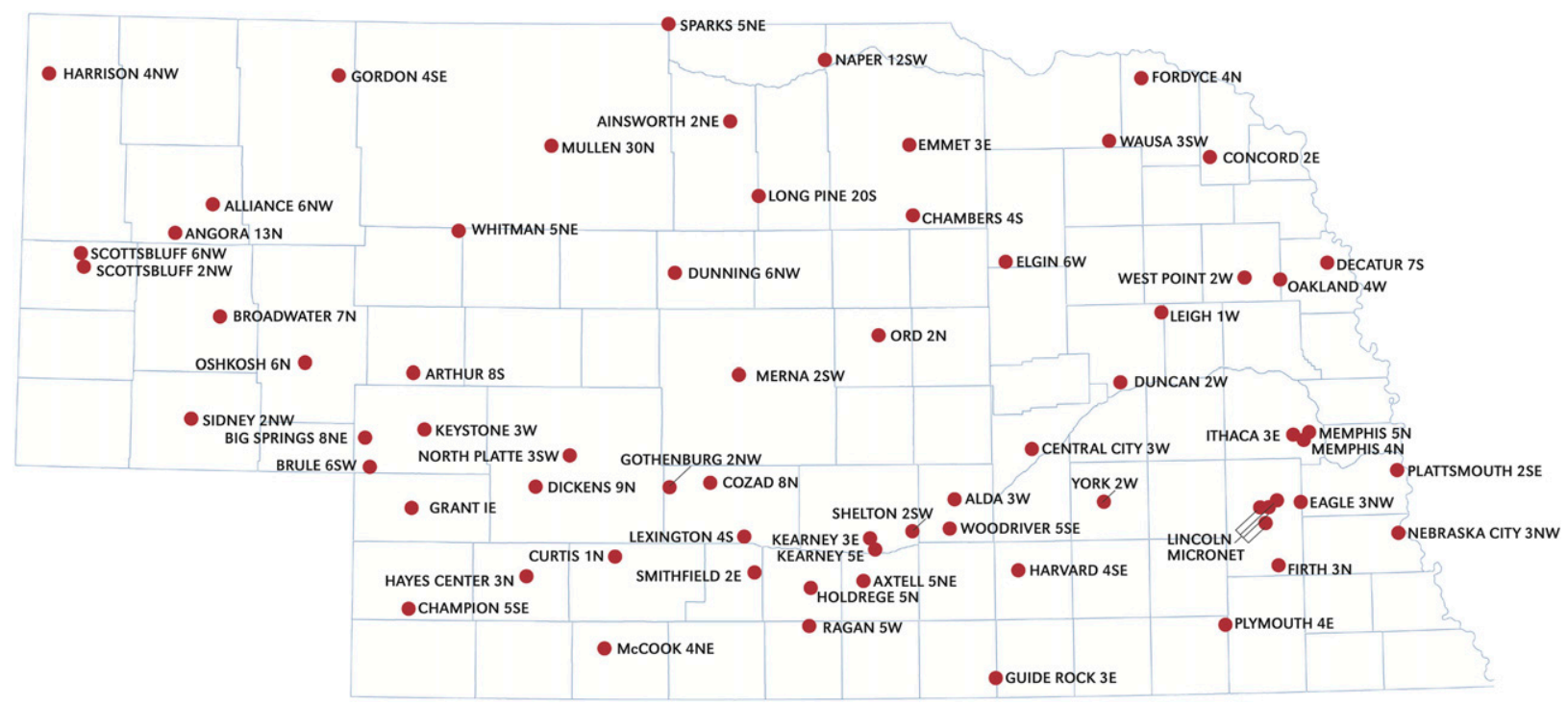

FIG. 1. Locations of Nebraska Mesonet stations as of 2018.

In 1981, a team at the University of Nebraska-Lincoln established a near-real-time weather network to support agriculture in the state of Nebraska, termed the Automated Weather Data Network (Hubbard et al. 1983). A workshop for data users identified agricultural uses such as livestock, forestry, pest management, irrigation scheduling, and cropping systems (Weiss 1981) to be of primary interest. At the time, state-of-the-art instrumentation and computing were utilized with a oncedaily communication with each weather station via telephone line. A mainframe computer at the Center for Agricultural Meteorology and Climatology archived all of the data in a system known as the Agricultural Management Network (AGNET).

Beginning in 2016, the Nebraska State Climate Office (NSCO), located in the School of Natural Resources at the University of Nebraska-Lincoln, began operating the state mesonet with a subsequent name change-the Nebraska Mesonet. This paper provides a technical overview of station configuration, sensor components, data flow, and data utility in an update to Hubbard et al. (1983).

\section{Mesonet overview}

Mesoscale observations in Nebraska began as a means to supplement federal observing programs with weather and climate information better tailored to agricultural production. There was a need for soil temperature information (to inform such decisions as timing of planting crops) as well as observations (such as incoming solar radiation) that could result in an estimation of evapotranspiration. Four of the first five locations in the mesonet were concentrated in southwest Nebraska"Champion 5SE," "Dickens 9N," "McCook 4NE," and "Brule 4SW"- with the remaining location in southeast Nebraska, "Ithaca 3E." At present, 69 stations comprise the mesonet with 45 of Nebraska's 93 counties having representation (Fig. 1). The growth in station number has increased fairly steadily over time and has largely been a function of identified local observation need and interest of individual station clients (Fig. 2). As is evident from Fig. 2, the exact number of stations that comprise the mesonet varies from year to year.

A total of 27 unique agencies and organizations currently provide a client base to pay for the station maintenance, including 9 entities within the University of Nebraska-Lincoln. These represent both public and private entities that have an expressed interest in highquality and timely local weather observations and data products. The primary motivations for the clients to contract NSCO are to improve water management decisions (both surface and groundwater), inform agricultural and environmental research, advise in farm management decisions, and provide soil moisture and precipitation for municipal flood control decisions.

Financial support through client relationships for measuring environmental parameters is critical to the operations of the mesonet and provides a significant source of funding. The current rate on a per station basis is $\$ 2,600$ per year. This charge covers all necessary requirements to maintain a station, including transportation to and from the location, communications, calibration services, sensor replacement as needed, and mesonet staff salary for data services (data capture, storage, and delivery to clients). The total mean time 


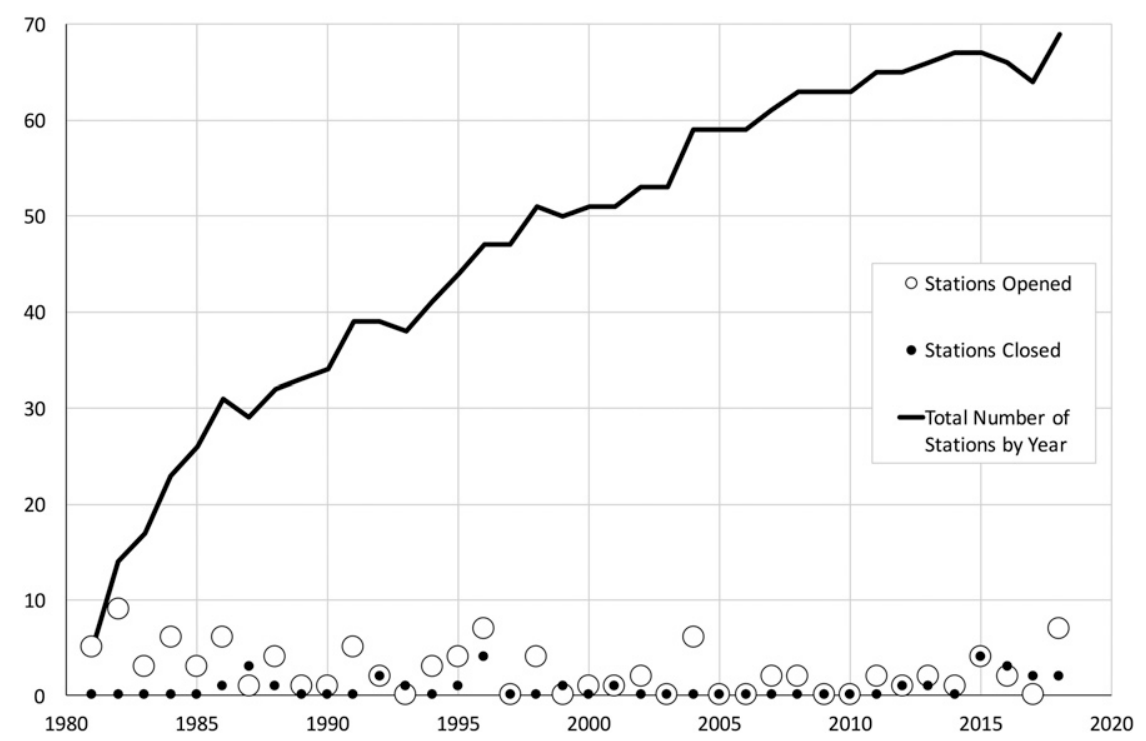

FIG. 2. Time series plot of the number of stations in the Nebraska Mesonet by year.

between failure (MTBF) per mesonet station was assessed in 2014 at 10 years, with some components aging at a much faster rate and others at a slower rate. In practice, it is assumed all components of a mesonet station will be replaced at least once within a $10-\mathrm{yr}$ period, and $\$ 2,000$ per year of the total rate is for the amortization of the cost to replace mesonet station components over that $10-\mathrm{yr}$ period. By using the concept of an MTBF, the annual fee remains constant to aid budgetary planning for clients. The remaining $\$ 600$ per year is the assessed cost of fuel, tools, vehicle leasing, lodging for extended field work, and other costs associated with the day-to-day operations of the mesonet. As a matter of comparison, the cost at the inception of the mesonet was $\$ 500$ per year per station. The current client rate per location took effect in 2016 after an evaluation of operations costs.

\section{a. Station design and equipment}

The design for mesonet stations at the inception of the program in 1981 was a 3-m tripod configuration, typical for many mesoscale weather observing programs. This design concept is still in use today across the mesonet (Fig. 3). The sensors, dataloggers, and communications devices utilized are all commercial off-the-shelf (COTS) available equipment commonly used in mesoscale observing programs. Table 1 outlines the sensors currently used in the mesonet. The equipment has evolved over time as technology has advanced and sensors are aged out and replaced with newer models.

At the onset of the mesonet, neither soil moisture nor atmospheric pressure was observed. Those sensors were added at a later date as prompted by funding and need.
In 1998, the mesonet began implementation of soil moisture sensors across the mesonet in stages. Sensors were initially installed at depths of $10,25,50$, and $100 \mathrm{~cm}$. By 2005, a total of 51 stations were equipped with soil moisture sensors (Hubbard et al. 2009). The impetus for this mesonet enhancement was improved climate and water supply monitoring for drought mitigation support (Svoboda et al. 2006) and made possible through a grant from the U.S. Bureau of Reclamation. Initially, Stevens-Vitel HydraProbe soil moisture probes were utilized. Because of issues with reliability, the Nebraska Mesonet transitioned to Dynamax ML2x Theta Probes, starting in 2001. Many are still in place, with 196 of the ML2x probes deployed across 49 mesonet stations.

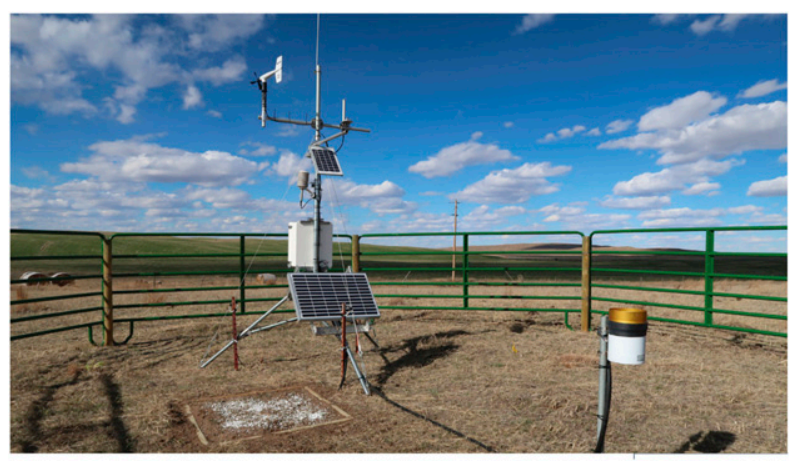

FIG. 3. Station photo illustrating tripod configuration, equipment, and cattle panel configuration at the Arthur 8S Nebraska Mesonet site. The photo was taken at the conclusion of annual maintenance on 16 Jun 2017. 


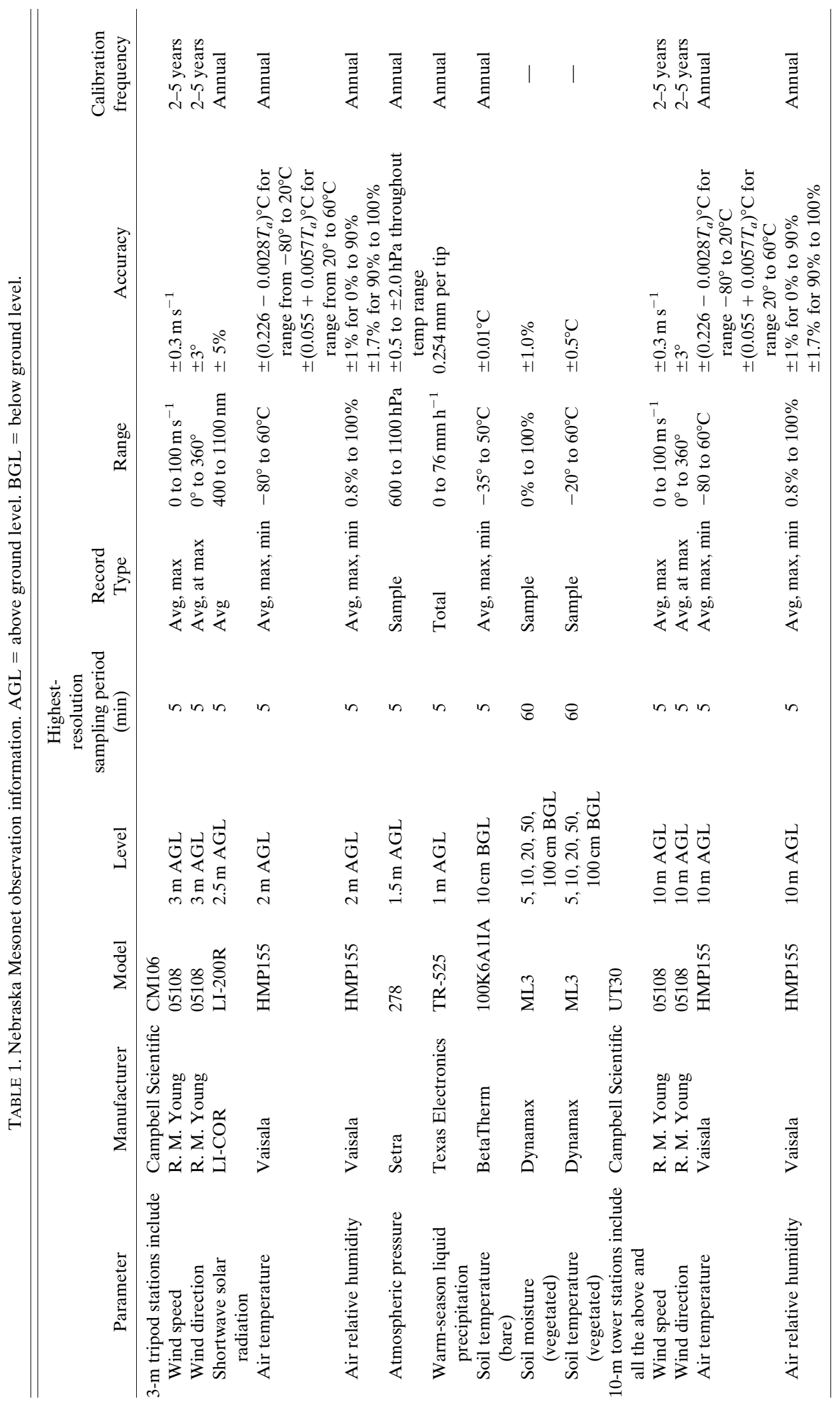


At present, the Nebraska Mesonet is transitioning to a new soil moisture configuration. To conform with USDA National Resources Conservation Service (NRCS) soil depth implementations, five depths of 5,10, 25,50 , and $100 \mathrm{~cm}$ are installed at new mesonet stations and in response to reinstallations at sites of damaged soil probes. The latest ML3 Theta Probe is utilized, which includes a soil temperature component as well as soil moisture. This allows for identification of when the soil is below freezing at the level monitored, along with soil energy flux estimations.

The sensors are installed by trenching down $1 \mathrm{~m}$, leaving an undisturbed end wall, from which soil samples are extracted for analysis. The probes are then inserted into the end wall to maintain the integrity of the soil column. Soil samples at each depth are obtained as instructed in the ML3 manual, which includes collecting a known volume of damp soil via a soil corer, no larger than $400 \mathrm{~mL}$; sealing the sample; and transporting it to the NSCO calibration laboratory for weighing, drying, and reweighing. Following this procedure, they are taken to the USDA National Soil Survey Center for further soil analysis. As such, detailed physical properties are obtained for each sample, including bulk density, particle size distribution, $15000-\mathrm{hPa}$ water retention, organic carbon, rock fragments, and others. This allows for a comprehensive understanding of soil characteristics and ultimately improves the public soil moisture product with calculable values, including water content of the soil (percentage saturation).

Most recently, and as a way to broaden mesonet utility for weather forecasting and other uses, atmospheric pressure sensors were added to the stations. These were installed during the summer of 2015 across the mesonet. Other than soil moisture and atmospheric pressure, the same observations (i.e., the parameters listed in Table 1) have been taken over the life of the mesonet. Specific sensors, however, are phased out either when no longer manufactured or when a cost-effective new sensor is found to be of superior quality. An example of this type of sensor change across the mesonet came in 2016. The wind speed and direction sensors previously used by the mesonet experienced freeze up during specific cold season weather events. This occurred several times per year in which the wind speed artificially reported zero because of icing. A switch was made during the 2016 maintenance season to a more durable wind sensor (R. M. Young 05108).

The footprint for each station is $84 \mathrm{~m}^{2}$. Orientation is such that the solar radiation sensor is mounted on a 0.6- $\mathrm{m}$ boom at $2.5 \mathrm{~m}$ above ground level facing south. Placement of the temperature and humidity probes is in a nonaspirated gill shield at $2 \mathrm{~m}$ above ground level. The tipping-bucket rain gauge is placed $3-4 \mathrm{~m}$ south of the tripod. Bare soil temperature is observed at the 10-cm depth within a $1 \mathrm{~m} \times 1 \mathrm{~m}$ box typically located 1-2 $\mathrm{m}$ southwest of the station base. Soil moisture and temperature probes are placed $2-3 \mathrm{~m}$ southeast of the station base, at the depths of 5, 10, 20, 50 , and $100 \mathrm{~cm}$. Many stations incorporate the use of a fence at a distance of $4-5 \mathrm{~m}$ from the station, which is primarily to prevent animal intrusions. The most effective and efficient fence type utilizes six 3.6-m "cattle panels" mounted against 15 -cm-diameter wooden fence posts.

The 3-m tripod is currently the standard station configuration. However, an effort to modernize the design and to conform to other mesoscale networks in operation, $10-\mathrm{m}$ towers are implemented when possible through additional funding. Currently, three stations in the mesonet are towers: "Lincoln 1500 North 45th," "Eagle 3NW," and "Leigh 1W." The former is located on the campus of the University of Nebraska-Lincoln and was upgraded from a tripod to a 10-m tower in 2016. The Eagle station is the Mesonet's research and development site, where new equipment is tested prior to implementation across the mesonet. The Leigh station was installed in 2018 as a tower because of an expressed need by the station sponsor for two levels of wind and temperature observations. The footprint for a $10-\mathrm{m}$ tower is $188 \mathrm{~m}^{2}$.

The mesonet stations are almost solely solar powered because of their predominantly rural locations. At present, most stations are equipped with one $10-\mathrm{W}$ solar panel coupled with a 7 amp hour (Ah) battery for powering the logger and one 50-W solar panel coupled with a 34-Ah battery for powering the cellular phone modem. A few stations have 20-W solar panels coupled with the 34-Ah battery. With the current sensor configuration, this is adequate to maintain performance while still being able to operate during midwinter cold and low sun angle. The reliance on solar power somewhat constrains the utilization of certain equipment on the stations, such as heated precipitation gauges, or continuous atmospheric pressure monitoring. Campbell Scientific CR1000 dataloggers are used for data storage and power management. Campbell Scientific dataloggers have been utilized since the mesonet inception. Communication for all stations is via cellular phone modem. This method was transitioned from landline telephone modem starting in 2014, completed at the end of 2015. Data are downloaded every $20 \mathrm{~min}$ to a secure server located at the University of Nebraska-Lincoln campus, with backup using Amazon Elastic Compute Cloud (EC2) cloud computing services. Security of the communications is enhanced with the ongoing implementation of a 
virtual private network (VPN) to each cellular phone modem through the primary cellular phone vendor.

Air temperature and relative humidity $(\mathrm{RH})$, atmospheric pressure, and wind speed and direction sensors are calibrated at the NSCO calibration laboratory. Calibrations have been performed at the University of Nebraska since the mid-1990s and follow the frequency of the corresponding manufacturers' recommendations. Temperature instruments are checked for calibration using a Jofra Instruments temperature calibrator RTC157. Relative humidity sensors are tested with LI-COR LI-610 dewpoint generators, custom-made manifolds, and specialized datalogger programs. Offsets determined during testing are applied to the individual station logger programs specific to the instrument deployed. Station pressure calibration is completed using the Druck PACE 5000 pressure controller and the Druck PACE CM2-B barometric control module. Wind instrument calibrations are performed using the R. M. Young Anemometer Drive and Vane Angle Bench Stand; however, fine tuning of wind calibrations is obtainable using an in-house wind instrument centrifuge, engineered in-house in the 1990s. For calibration of the LI-COR solar radiation sensors, a methodology developed in the 1980s is utilized currently (AcevesNavarro et al. 1988). These calibrations are performed on the roof of a 10-story building on the university campus. Up to 72 silicon cell pyranometers can be calibrated simultaneously with a manufacturer-calibrated Eppley Precision Spectral Pyranometer (PSP) used as the control.

A robust equipment and event inventory is maintained by the NSCO via a relational database management system (RDBMS). Each component in the field, laboratory, or storage is catalogued and readily accessible by mesonet staff. This allows for an easy and quick metadata reference for use in troubleshooting, tracking calibration dates, and knowing when to phase out sensors, as well as conforming to state statute on appropriate tracking of inventory. Another key piece of metadata is a photo history. Digital photographs are taken of each station and the surrounding landscape every year, as outlined in section $2 c$. Over time, these records have been found to be beneficial in the event that any questions arise over the station microclimate and tracking land-cover and land-use change over time.

\section{b. Siting considerations}

The location of mesonet sites are mostly rural and rarely in suburban or urban environments. A notable exception is the "Lincoln Micronet," in which five stations are located within the city of Lincoln. In general, station locations across the mesonet are determined by places in which station clients are in need of environmental monitoring. The interests of client needs have determined the overall spatial configuration of the mesonet. As noted in Fig. 1, there is not necessarily an even spatial distribution across the state. The central Platte River valley is the most densely sampled part of the state, whereas the northern half and extreme southern tier of the state are the most sparsely sampled. Agencies and organizations with vested interests in water management are primary station clients. Natural resource districts (NRDs) in Nebraska, which represent a system of local resource management governance by river basin, categorically contract a large number of monitoring locations across the state (23). Other interests include University of Nebraska Regional Research and Extension Centers, the Institute of Agriculture and Natural Resources, the private sector, and research applications.

When determining the exact location of a station in a given area, several factors are considered. Key starting points include land owner cooperation, accessibility by service vehicle, security, current and future area use, and longevity. The scoring sheet (Fig. 4) is used as a guideline on the desirability of a particular site. A higher score would indicate a more desirable site, especially if more than one site is being considered for a new station. This scoring sheet has been utilized for siting stations since the mid-1990s and follows NOAA guidelines. The variables of temperature and humidity, precipitation, wind, and solar radiation are considered individually in the scoring sheet. As is evident from the table, the location factor that plays a role for each variable is the angular height of nearby obstacles. For this metric to score high, it needs to be less than $15^{\circ}$ above the horizon for precipitation, and $5^{\circ}-7^{\circ}$ for the other variables. For temperature, the distance from artificial heating sources and large bodies of water is ideally greater than $300 \mathrm{~m}$. Points are given for each classification metric per variable and then summed to provide a total score for each location. The score determines the class category, of which there are five, classes 1-3 (100-40 total points) being acceptable while classes 4 and 5 are deemed unacceptable locations (less than 40 total points).

Stations not located within the city limits of Omaha or Lincoln are named according to the following rules. Location name is the closest village, town, or city, using the closest post office associated with this feature, based upon the U.S. Board on Geographic Names database. If the station is located more than $0.5 \mathrm{mi}(\sim 0.8 \mathrm{~km})$ from a post office, a distance and direction suffix is added to the name that will provide the closest whole mile and cardinal direction from the post office to where the station 


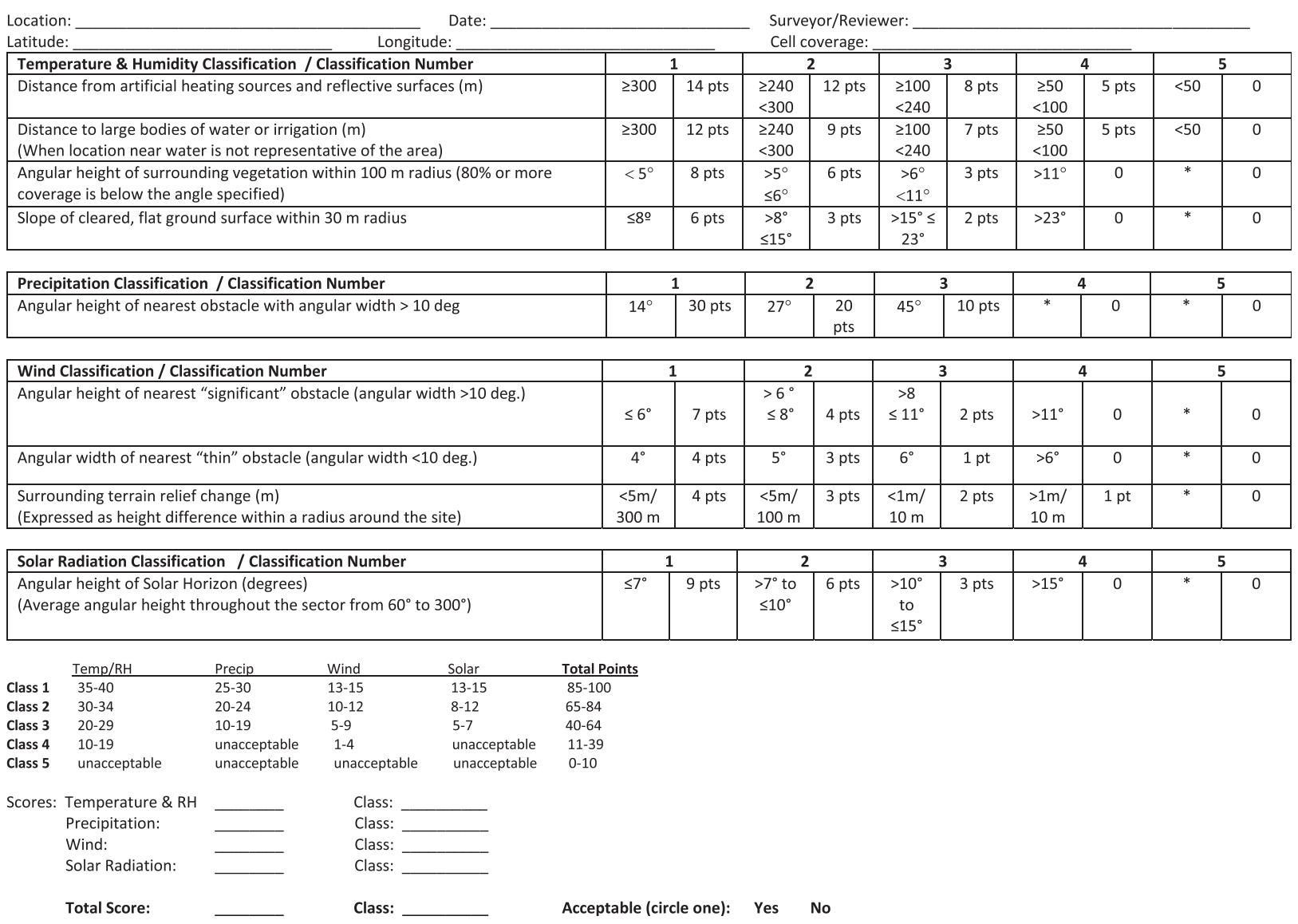

FIG. 4. Nebraska Mesonet site survey score sheet.

is located. Multiple stations that have the same name by these rules will be given an additional suffix identifier using Greek letters, starting with alpha. Urban stations (i.e., Lincoln and Omaha) will be named using first the city name, the block number of the closest north-south street, and the closest north-south street.

\section{c. Station maintenance}

A critical component of mesonet operations is consistent and regular station maintenance. Through the life of the Nebraska Mesonet going back to 1981, there has been good continuity and institutional knowledge in maintenance, as well as calibration practices, with only three full-time (nonoverlapping) field and calibration technical staff. A single field technician has maintained all stations since the mesonet's inception. Each station is visited by the technician on an annual basis for scheduled maintenance activities. Annual maintenance periods typically begin in late March and continue as weather permits into late October. If any data issues, sensor failures, etc. arise at any point in the year, however, a station will be visited to address the issue outside of the scheduled maintenance.
A standardized procedure as outlined on a maintenance sheet is followed across the mesonet. Upon arrival at a site, the time is documented and, if desired, a set of station photos is taken. A walk-around is then completed, with visual inspection of the station integrity, and particular notations made if the area proximal to the station has changed in any way. More scrutiny of the station structure and sensor area is then completed and any potential issues are documented on the maintenance sheet. The station datalogger is then placed into "maintenance mode," which sets a flag within the stored data of the time maintenance initiates and completes for a station that may affect instrument readings. The station footprint is mowed such that the vegetation is at a height of approximately $10-15 \mathrm{~cm}$, dependent upon the vegetative type. The mowed debris is then raked and removed from the station footprint. Any vegetation growing in the bare soil box is removed by hand. A thermometer with a demarcation at the $10-\mathrm{cm}$ level is then inserted into the bare soil box. After about a half hour, this reading is then documented and compared to the thermistor to check for consistency of observations. If values are not within a few degrees Celsius, a bare soil sensor may be replaced. 
Solar, temperature and humidity, and pressure sensors are swapped with freshly calibrated sensors at least once per year. The outgoing sensor readings are documented prior to removal, and checked against the replacement sensor readings, once in place, to check for consistency. The serial numbers of the respective sensors (both outgoing and incoming) are documented on the maintenance sheet. The precipitation gauge is visually inspected and any potential issues are documented. The funnel and screen are removed and cleaned using a brush and distilled water. Any dents in the screen are smoothed using a rubber mallet. The tipping-bucket housing unit is checked for level and any debris in the "bucket" is removed. A pipe cleaner is used to check for spider webs or other debris around the tipping mechanism that would prevent tipping. A calibrated syringe is used to ensure the mechanical "tips" occur when filled with the precise amount of water. If not, the unit level is adjusted accordingly. Power supplies and batteries are spot checked (although the same data are also logged by the datalogger as part of the data collection). Batteries are replaced on a schedule approximately every 2 years, or if there is an indication of imminent failure. Once all items are checked, and just before the enclosure for the station is resecured, the station datalogger is taken out of maintenance mode.

Photographs are taken at the conclusion of maintenance activities. Three closeup views of the entire station are taken, including vegetation close-ups. Approximately $30 \mathrm{~m}$ from the station, photos are taken of the station footprint from eight cardinal directions. Subsequently, the same angle of photographs is taken from the station looking outward such that the surrounding landscape is documented.

Common field issues and problems that arise and require mitigation at the site visits are primarily from animal intrusions, both above and below ground. Typical issues include soil sensors exhumed, pecking or chewing of wires or tie wraps, and station structures used as scratching posts. Vandalism is a rare issue for the mesonet and has not been a major concern. Sensor failure from weather-related hazards are also not common. Lightning has destroyed station electronics, with physical integrity compromised by tornadoes and straight-line high wind, hail, and wildfire. Each of these station integrity issues (averaging fewer than $5 \mathrm{yr}^{-1}$ ) are addressed as they arise.

\section{d. Data quality checks}

Quality control is a critical step in postprocessing of mesonet data. All incoming data are preserved; however, data may be categorized as missing from the publicly available record if it fails one or more of the checks. While the precipitation tipping buckets are unheated and therefore not able to measure frozen precipitation, winter observations are nonetheless preserved in original form in the event of a liquid precipitation event during the winter months. Data are collected and stored at each location by a local datalogger in 5-min bins. Every $20 \mathrm{~min}$, the Nebraska State Climate Office servers query the local datalogger to download all data since the previous download. Raw data are stored in a flat file system, whereas the data are also decoded in real time, with decoders. Upon retrieval from the datalogger, the data quality process is as follows:

1) Automatic-Initial values for each parameter measured are compared to an appropriate range for the variable being measured, regardless of climatology, and flagged if outside of the range, with an alert sent to NSCO staff.

2) Automatic-Initialization grid and/or other gridpoint interpolation alignment. Specific parameters are extracted from hourly NCEP model initialization or gridded NEXRAD precipitation data and then compared to mesonet observations collected, with flags raised for values more than defined deviation from the control. The allowable deviation criteria are parameter specific, and in the case of precipitation, two factors are in play to create a binary affirmation to the validity of a precipitation reading - that is, if the nearest NEXRAD was operating and if the NEXRAD detected precipitation for the same time.

3) Manual-Mesonet data are gridded and then graphically layered with data from other sources, such as Automated Surface Observing System (ASOS) stations, and visually inspected for deviations or values that do not appear to fit the atmospheric regime at the time of the observation. Values falling outside of the perceived visual inspection are flagged.

4) Manual-Client and antidotal feedback. Feedback from stakeholders that use the mesonet data that signify collected values that depart from reality will initiate an examination of the data, collection of further information of the reported incident, and possibly flag the data if found in error.

Data points that are flagged as suspect, either in the automatic or manual process, remain in the database, but they are not released to the public or used in the computation of value-added products. Breaking from operating procedures of other mesonets or climate data networks, no attempt is made to create estimated data for points found to be suspect or in error.

\section{Mesonet products, customers, and utility}

In addition to the specific parameters measured in the mesonet, there are data products developed from these 
observations. A reference evapotranspiration $\left(\mathrm{ET}_{\text {ref }}\right)$ value is computed daily. This parameter is calculated using the Penman-Monteith equation (Allen et al. 1998), utilizing the daily maximum air temperature, minimum air temperature, maximum relative humidity, minimum relative humidity, average downward shortwave solar radiation, average wind speed, average station pressure, elevation of the station, latitude of the station, and Julian day of year. Modified growing degree-days (GDDs) are calculated daily using the upper and lower thresholds of $30^{\circ}$ and $10^{\circ} \mathrm{C}$, respectively. The daily values are then accumulated throughout the course of the growing season to provide agricultural interests with up-to-date information, with starting dates of 1 April, 15 April, and 1 May, giving farm operators start dates to interpolate values specific to their plant date. Instantaneous wind chill, dewpoint, and heat index values are calculated on the loggers, with average, maximum, and minimum values stored for collection per 5 -min bin. The cattle comfort index is calculated on NSCO servers each hour, utilizing the methodology outlined in Mader et al. (2010). This index is useful during both heat and cold extremes. An example suite of products designed to suit agricultural interests are shown in Fig. 5.

Real-time mesonet observations are made available online for the public free of charge (https://mesonet.unl. $\mathrm{edu} /$ ). These data are provided in tabular and mapped formats. Hourly data are posted (and replace the previously posted observations) at approximately $10 \mathrm{~min}$ past the hour. The only nonmesonet data provided online in a real-time manner are visible satellite imagery from GOES-East, via the National Oceanic and Atmospheric Administration (NOAA). Daily summary maps are also posted online free to the public. The following parameters are available just after midnight, local time, and are calculated over the previous 24-h period: maximum, mean, and minimum air temperature; maximum wind gust; total precipitation; and mean $10-\mathrm{cm}$ bare soil temperature. During the growing season, daily values of the GDD accumulations for three different starting dates and $\mathrm{ET}_{\text {ref }}$ are also posted. Nonmesonet data posted on a daily basis are NEXRAD estimated daily, weekly, monthly precipitation totals.

Clients and customers of mesonet data and products originate from a variety of sectors. Direct data requests from individuals and organizations not served through the currently available online products described above are tracked and catalogued. Information from the mesonet are documented to be used in a range of decision-making. Primary data users at the local, state, and national level include the following: irrigation scheduling, crop water use assessment, herbicide application decision support, human and animal health assessment, ground and surface water management, risk analysis, emergency management mitigation and response, energy demand and resource allocation, weather forecasting and warning operations, flood and drought assessments, educational programming, identification of current and emerging climate issues, and research support.

There has been a long-standing relationship between the mesonet and the University of Nebraska Extension community. These interests are served with weather stations at the three Regional Research and Extension Centers in Nebraska as well as agricultural and landscape facilities around the state. Data and products from the mesonet are heavily utilized by local University of Nebraska Extension personnel at both the regional and county levels to serve their constituency. Mesonet products are posted daily to the University of Nebraska Extension web portal CropWatch (https://cropwatch. unl.edu/). According to web statistics, the mesonet products with the greatest number of views are the daily and weekly average bare soil temperature. This information is of high importance during the spring planting season to determine when the temperatures are suitable for seed germination. At the 10 locations in which soil temperature is also observed under grass at $10 \mathrm{~cm}$ (in conjunction with soil moisture), a temperature difference between the two ground covers is also posted. Wind speed and direction are a highly requested product within the University of Nebraska Extension community for aerial herbicide application and determining the potential for spray drift. A mobile application (app) developed by University of Nebraska Extension personnel-AgriTools-utilizes mesonet data and products. It is free for download on Apple and Android systems. The app provides location-specific information on livestock, crops and irrigation, pest management, and climate and weather for Nebraska.

Nebraska Mesonet data have been used extensively in research applications. An investigation of peer-reviewed research reveals that since 1981, a total of 140 publications have documented utilization of mesonet data. The research themes include the following categories: agriculture, water (surface and groundwater), ecology, health, and weather and climate.

Natural resource districts are a significant user of mesonet data. Utility for the NRDs are primarily for aiding water management decisions, such as groundwater sustainability plans and irrigation usage. Specifically, NRDs use the data to provide inputs to crop water-use models that compute monthly pumping and groundwater recharge volumes for groundwater aquifer storage analysis. Nebraska benefits from the rich 

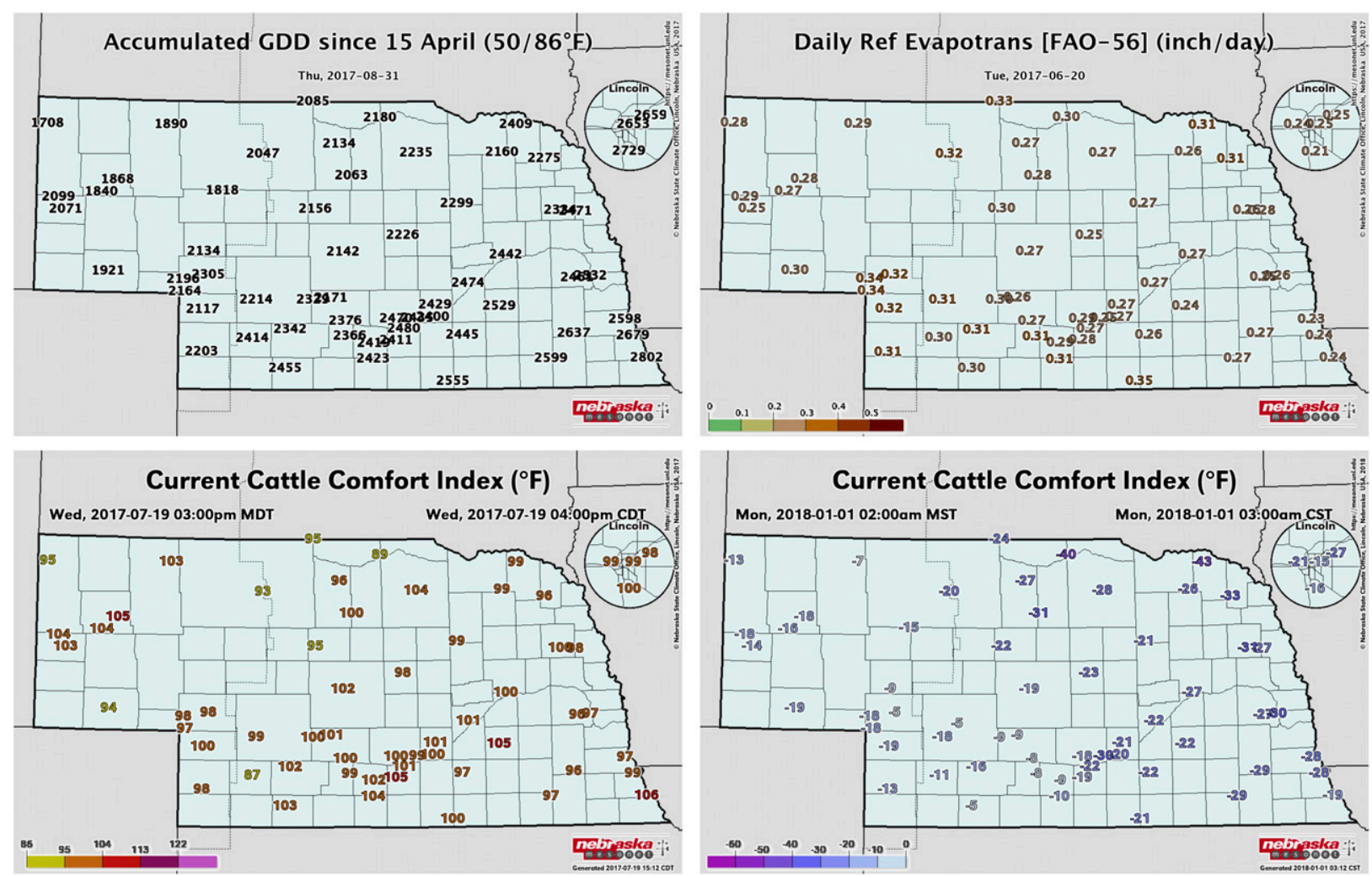

FIG. 5. Examples of mesonet data products calculated and posted online: (top left) accumulated GDDs as of 31 Aug 2017 with a 15 Apr start date, (top right) daily reference evapotranspiration (in.; 1 in. $=2.54 \mathrm{~cm}$ ) for 20 Jun 2017, (bottom left) real-time cattle comfort index maps on the afternoon of $19 \mathrm{Jul}$ 2017, and (bottom right) early morning on 1 Jan 2018.

groundwater resources with the High Plains aquifer (as well as surface water), and irrigation usage is widespread throughout the state to augment growing-season precipitation and to allow for viable cropping systems. As of 2017 , more than $33000 \mathrm{~km}^{2}$ of harvested cropland and pasture are irrigated. The number of active registered irrigation wells currently stands at 96131 .

Successful water management relies in part on robust environmental observations provided through this mesonet. As such, the Nebraska Department of Natural Resources is also a primary user of the data. In particular, historical and real-time data are utilized for the agency's Integrated Water Management Plan activities in which the department works with NRDs at the basin level to achieve balance between water supply and usage. An understanding of irrigation water requirements (with the aid of mesonet data) is used to model the interactions of hydrologically connected groundwater and surface water. Furthermore, mesonet data help Nebraska meet with requirements of a U.S. Supreme Court decree between Nebraska, Wyoming, and Colorado, and the U.S. Bureau of Reclamation regarding water of the North Platte River. Similarly, data are also used for water accounting requirements of an interstate compact between Nebraska, Colorado, and Kansas regarding waters of the Republican River.

Within the growing season, mesonet data are used by the University of Nebraska Extension and the farming community for irrigation management through an online tool, CornSoyWater, developed by researchers at the University of Nebraska (http://hprcc-agron0.unl. edu/cornsoywater/public_html/Home.php). Nebraska Mesonet data are assimilated on a daily basis for the purpose of identifying crop water use and providing recommendations for irrigation application. The tool is Nebraska-specific at present.

The state of Nebraska established a Climate Assessment and Response Committee in 1991, which is managed by the Nebraska Department of Agriculture. Within this assessment and response committee is a Water Availability and Outlook Committee designated to monitor current and estimate future water availability and moisture conditions. The committee meets quarterly, and Nebraska Mesonet data and products are used to provide historical and real-time weather and climate assessments. Situation reports and recommendations of the committee are provided to the governor. 
Weather information is used extensively by the Nebraska Emergency Management Agency, supporting its Watch Center. This group provides current situational awareness and daily electronic briefings of weather and hazard conditions for a number of different agencies statewide. The briefing is sent electronically to 300 recipients working in emergency management and public safety.

Mesonet data are delivered in real time to the National Oceanic and Atmospheric Administration via the Meteorological Assimilation Data Ingest System (MADIS). As such, the NOAA research community and National Weather Service (NWS) operations are able to incorporate Nebraska Mesonet data into their systems and applications. The spatial density provided by this mesonet, along with federally managed networks, allows for the detection of smaller-scale (and high impact) processes that occur, such as thunderstorms and heavy convective precipitation. Several instances in the past year alone have allowed NWS offices to verify citizen reports of severe weather, including extreme wind. On 14 May 2017, a downburst-producing thunderstorm tracked across a data-sparse region in northwest Nebraska, with citizen reports of high winds. The Harrison 4NW Nebraska Mesonet station recorded a $42 \mathrm{~m} \mathrm{~s}^{-1}$ wind gust to verify the positive reports. Soil moisture information is a key parameter requested by the NWS in the production of its flood outlooks. Data have been delivered to NOAA since February 2017.

Mesonet data are transmitted on a daily basis to the High Plains Regional Climate Center (RCC), to be included in the RCC Applied Climate Information System (ACIS; Hubbard et al. 2004). ACIS is a data distribution system maintained by the RCC program with many operational functions in applied climate, water management, and drought mitigation. Through ACIS, the data are available to a national audience. In addition, the HPRCC utilizes Nebraska Mesonet data in its calculation of agronomic decision support information for dissemination to its client base. Furthermore, the High Plains RCC performs manual and automated quality control checks on a daily basis, as outlined by Hubbard et al. (2005) for Nebraska Mesonet as well as other state mesonet data acquired by the center.

In looking at the future of the program, the immediate goal of the Nebraska Mesonet is to expand the current network to provide the best possible data distribution for the benefit of local stakeholders, including a geographic distribution of stations that fits well with weather model initialization. To best serve mesonet clients and users, a survey will be distributed to systematically assess data and product usage. The intent will be to gauge current product utility, to understand specific decisions the data and products inform, and to attempt to put an economic value on the products. Furthermore, the formation of a mesonet advisory board is being considered as a mechanism to garner external perspectives on maximizing operational efficiency and guide long-term planning. To optimize station density, a general rule of one station per county (of which there are 93 in Nebraska) is the approximate goal. This would translate to roughly one station every $80 \mathrm{~km}$. Another goal is the implementation of $10-\mathrm{m}$ towers to further enhance data collection capabilities and conform to other mesonet programs, as well as other weather monitoring agencies, in the United States.

\section{Summary}

The Nebraska Mesonet represents one of the first statelevel weather networks in the United States. While originally designed with agricultural interests in mind, the mesonet has benefited from steady growth in station number over time and has transitioned to a broader environmental monitoring program. The same basic suite of meteorological variables has been measured since 1981. Soil moisture was added to the mesonet beginning in 1998 and atmospheric pressure implemented in 2015. Technology of the sensors, solar power, dataloggers, communications, structural components, and data storage techniques used in the program has evolved over time with upgrades as needed and as funding allowed. As is the case for other mesonet programs in the United States, data and products (both historical and real time) are currently utilized by a broad user base to aid in many forms of weather-sensitive decisionmaking. The users and products utilized are tracked in an effort to document the utility of such a program.

Because the Nebraska Mesonet has been in place for several decades and the maintenance, calibration, and quality control efforts are all part of the metadata, the record length of many stations is such that historical trend analysis can be performed. By siting stations primarily in rural landscapes, the station footprints have generally remained consistent over time. Therefore, land-use change has not played a significant role as a factor biasing trend analyses. Locations are sited on native or planted vegetation (grass), as opposed to cropland. Given the spatial distribution of stations in the mesonet, the most common land use outside of the station footprint would be row cropping systems, for example, corn-soybean rotation. Irrigation, mainly through center pivots, is utilized extensively across Nebraska, and stations in the mesonet are not immune to secondary impacts of water applied to nearby fields (such as the influence on humidity).

Operations of a mesonet are inherently fluid as new stations are installed nominally on an annual basis and stations can close because of loss of funding, a landowner change, or mesonet staff may choose to relocate a 
station to improve siting classification. To advance station configurations and best management practices, it is the goal of the mesonet to continually test new equipment at the research and development site for performance and possible implementation across the mesonet. Federal standards from agencies such as NRCS and NWS will also continue to be considered so as to homogenize weather monitoring standards across the United States so the needs of data users can be effectively fulfilled.

Acknowledgments. Shulski received financial support from the Institute of Agriculture and Natural Resources at the University of Nebraska-Lincoln and the Nebraska Department of Natural Resources, Award 1001.

\section{REFERENCES}

Aceves-Navarro, L. A., K. G. Hubbard, and J. Schmidt, 1988: Group calibration of silicon cell pyranometers for use in an automated network. J. Atmos. Oceanic Technol., 5, 875-879, https://doi.org/ 10.1175/1520-0426(1988)005<0875:GCOSCP > 2.0.CO;2.

Allen, R. G., L. S. Pereira, D. Raes, and M. Smith, 1998: Crop evapotranspiration-Guidelines for computing crop water requirements. FAO Irrigation and Drainage Paper M-56, 300 pp.

Boselly, E. S., III, G. S. Dore, J. E. Thornes, C. Ulburg, and D. D. Ernst, 1993: Road weather information systems: Research report, Vol. 1, National Research Council Strategic Highway Research Program Publ. SHRP-H-350, 219 pp.

Cifelli, R., N. Doesken, P. Kennedy, L. D. Carey, S. A. Rutledge, C. Gimmestad, and T. Depue, 2005: The Community Collaborative Rain, Hail, and Snow Network: Information education for scientists and citizens. Bull. Amer. Meteor. Soc., 86, 10691077, https://doi.org/10.1175/BAMS-86-8-1069.

Conlee, D. T., and P. F. Moersdorf, 2005: The NWS Marine Observation Network: Coastal marine component of multiple observing systems. Preprints, Ninth Symp. on Integrated Observing and Assimilation Systems for the Atmosphere, Oceans, and Land Surface (IOAS-AOLS), San Diego, CA, Amer. Meteor. Soc., 7.1, https://ams.confex.com/ams/Annual2005/ techprogram/paper_83171.htm.

Diamond, H. J., and Coauthors, 2013: U.S. Climate Reference Network after one decade of operations: Status and assessment. Bull. Amer. Meteor. Soc., 94, 485-498, https://doi.org/ 10.1175/BAMS-D-12-00170.1.

Elliott, R. L., F. V. Brock, M. L. Stone, and S. L. Harp, 1994: Configuration decisions for an automated weather station network. Appl. Eng. Agric., 10, 45-51, https://doi.org/10.13031/2013.25826.

Fiebrich, C. A., 2009: History of surface weather observations in the United States. Earth-Sci. Rev., 93, 77-84, https://doi.org/ 10.1016/j.earscirev.2009.01.001.

—, D. L. Grimsley, R. A. McPherson, K. A. Kesler, and G. R. Essenberg, 2006: The value of routine site visits in managing and maintaining quality data from the Oklahoma Mesonet. J. Atmos. Oceanic Technol., 23, 406-416, https://doi.org/10.1175/ JTECH1852.1.

Hubbard, K. G., N. J. Rosenberg, and D. C. Nielsen, 1983: Automated weather data network for agriculture. J. Water Resour. Plann. Manage., 109, 213-222, https://doi.org/10.1061/(ASCE) 0733-9496(1983)109:3(213).
— A. T. DeGaetano, and K. D. Robbins, 2004: A modern applied climate information system. Bull. Amer. Meteor. Soc., 85, 811-812, https://doi.org/10.1175/BAMS-85-6-811.

- S. Goddard, W. D. Sorensen, N. Wells, and T. T. Osugi, 2005: Performance of quality assurance procedures for an applied climate information system. J. Atmos. Oceanic Technol., 22, 105-112, https://doi.org/10.1175/JTECH-1657.1.

_ J. You, V. Sridhar, E. Hunt, S. Korner, and G. Roebke, 2009: Near-surface soil-water monitoring for water resources management on a wide-area basis in the Great Plains. Great Plains Res., 19, 45-54.

Mader, T. L., L. J. Johnson, and J. B. Gaughan, 2010: A comprehensive index for assessing environmental stress in animals. J. Anim. Sci., 88, 2153-2165, https://doi.org/10.2527/jas.2009-2586.

Mahmood, R., and Coauthors, 2017: Mesonets: Mesoscale weather and climate observations for the United States. Bull. Amer. Meteor. Soc., 98, 1349-1361, https://doi.org/10.1175/BAMS-D15-00258.1.

Manfredi, J., T. Walters, G. Wilke, L. Osborne, R. Hart, T. Incrocci, and T. Schmitt, 2005: Road weather information system environmental sensor station siting guidelines. Version 1, U.S. Federal Highway Administration Publ. FHWA-HOP05-026, 46 pp.

McPherson, R. A., and Coauthors, 2007: Statewide monitoring of the mesoscale environment: A technical update on the Oklahoma Mesonet. J. Atmos. Oceanic Technol., 24, 301-321, https:// doi.org/10.1175/JTECH1976.1.

Meyer, S. J., and K. G. Hubbard, 1992: Nonfederal automated weather stations and networks in the United States and Canada: A preliminary survey. Bull. Amer. Meteor. Soc., 73, 449-458, https://doi.org/10.1175/1520-0477(1992) $073<0449$ :NAWSAN>2.0.CO;2.

Nadolski, V. L., 1998: Automated Surface Observing System (ASOS) user's guide. NOAA, U.S. Department of Defense, Federal Aviation Administration, U.S. Navy, 74 pp.

Schaefer, G. L., and D. E. Johnson, 1992: Development and operation of the SNOTEL system in the western United States. United States/People's Republic of China Flood Forecasting Symposium/Workshop, Vol. 1, Office of Hydrology, National Weather Service, 29-48.

Schroeder, J. L., W. S. Burgett, K. B. Haynie, I. Sonmez, G. D. Skwira, A. L. Doggett, and J. W. Lipe, 2005: The West Texas Mesonet: A technical overview. J. Atmos. Oceanic Technol., 22, 211-222, https://doi.org/10.1175/JTECH-1690.1.

Shafer, M. A., C. A. Fiebrich, D. S. Arendt, S. E. Fredrickson, and T. W. Hughes, 2000: Quality assurance procedures in the Oklahoma Mesonet. J. Atmos. Oceanic Technol., 17, 474-494, https:// doi.org/10.1175/1520-0426(2000)017<0474:QAPITO>2.0.CO;2.

Svoboda, M., S. Korner, D. A. Wilhite, and M. J. Hayes, 2006: Enhancing Nebraska's state drought mitigation plan and drought monitoring capacity through improved soil moisture applications. National Drought Mitigation Center Project Rep., 13 pp.

Tucker, D. F., 1997: Surface mesonets of the western United States. Bull. Amer. Meteor. Soc., 78, 1485-1496, https://doi.org/10.1175/ 1520-0477(1997)078<1485:SMOTWU>2.0.CO;2.

Weiss, A., Ed., 1981: Computer Techniques and Meteorological Data Applied to Problems of Agriculture and Forestry: A Workshop. Amer. Meteor. Soc., 386 pp.

Zachariassen, J., K. Zeller, N. Nikolov, and T. McClelland, 2003: A review of the forest service remote automated weather station (RAWS) network. USDA Forest Service Rocky Mountain Research Station General Tech. Rep. RMRS-GTR-119, 153 pp. 